\title{
Vascular Apoptosis and Involution in Gliomas Precede Neovascularization: A Novel Concept for Glioma Growth and Angiogenesis
}

\author{
David Zagzag, Ramin Amirnovin, M. Alba Greco, Herman Yee, Jocelyn Holash, \\ Stanley J. Wiegand, Stephanie Zabski, George D. Yancopoulos, and Martin Grumet \\ Microvascular and Molecular Neurooncology Laboratory (DZ, RA); Department of Pathology, Division of Neuropa- \\ thology (DZ), Division of Surgical Pathology (HY), and Division of Pediatric Pathology (MAG), Department of \\ Neurosurgery (DZ), Department of Pharmacology (MG); Kaplan Cancer Center (DZ, MAG, HY, MG), New York \\ University Medical Center, New York, New York; and Regeneron Pharmaceuticals (JH, SJW, SZ, GDY), Tarrytown,
} New York

\begin{abstract}
SUMMARY: Vascular changes in gliomas were analyzed by implanting fluorescent-labeled glioma 261 cells in the brains of 28 mice. Seven animals were killed each week for 4 weeks. We investigated the expression of angiopoietin-2 (Ang-2) by in situ hybridization and compared it with the distribution of apoptotic cells identified by DNA strand breaks (using the terminal deoxynucleotidyl transferase-mediated biotinylated deoxyuridine triphosphate nick end labeling [TUNEL] method) and transmission electron microscopy (TEM). As early as 1 week after implantation, tumor cells accumulated around vessels, which expressed Ang-2 and were TUNEL negative. TEM showed tumor cells adjacent to the vascular cells "lifting up" the normal astrocytic feet processes away from the endothelial cells and disrupting normal pericytic cuffing. After 2 weeks the number of perivascular glioma cells had increased. No increase in the number of blood vessels was detected at this time. Vascular cells remained positive for Ang-2 and rare ones were TUNEL positive. TEM showed closely packed proliferating perivascular tumor cells. After 3 weeks, there was vascular involution with scant zones of tumor necrosis. Ang-2 was still detected in vascular cells, but now numerous vascular cells were TUNEL positive. In addition, TEM showed apoptotic vascular cells. After 4 weeks, there were extensive areas of tumor necrosis with pseudopalisading and adjacent angiogenesis. Ang-2 was detected in vascular cells at the edge of the tumors in the invaded brain and in vessels surrounded by tumor cells. At both 3 and 4 weeks, most of the TUNEL-positive tumor cells lacked morphological features characteristic of apoptosis and displayed features consistent with necrotic cell death as determined by TEM. Only rare tumor cells appeared truly apoptotic. In contrast, the TUNEL-positive endothelial cells and pericytes were round and shrunken, with condensed nuclear chromatin by TEM, suggesting that vascular cells were undergoing an apoptotic cell death. These results suggest that vascular cell apoptosis and involution preceded tumor necrosis and that angiogenesis is a later event in tumor progression in experimental gliomas. Moreover, Ang-2 is detected prior to the onset of apoptosis in vascular cells and could be linked to vascular involution. (Lab Invest 2000, 80:837-849).
\end{abstract}

A poptosis and angiogenesis are both critical events in the normal sequences of many biologic processes and play key roles in regulatory activities during normal and pathological processes including development and oncogenesis. Apoptosis and angiogenesis are as fundamental to cellular and tissue physiology as are cell division and differentiation. In contrast to necrosis, apoptosis may affect scattered individual cells rather than clusters of cells, entire tissues, or organ compartments (Majno and Joris, 1995). One of the key characteristics of apoptosis is

Received January 11, 2000.

Presented in part at the meeting of the American Association of Neuropathologists, Portland, OR, 1999, this investigation received the Lucien J. Rubinstein Award.

Address reprint requests to: Dr. D. Zagzag, Department of Pathology, Division of Neuropathology, New York University Medical Center, 550 First Avenue, New York, NY 10016. Fax: 212-263-8994; E-mail: zagzag@is3.nyu.edu cell shrinkage. Apoptosis represents a mechanism to remove damaged, infected, or unwanted cells selectively (Allen et al, 1998; Dinsdale et al, 1999; Payne et al, 1995; Wyllie et al, 1980).

Angiogenesis, ie, neovascularization, is a complex biological process whose regulatory mechanisms are not completely understood. Formation of new vessels occurs during embryogenesis, wound healing, and regeneration, but also in pathological processes, eg, neoplasia, diabetic retinopathy, and arthritis (Folkman, 1995; Yancopoulos et al, 1998). Angiopoietin-1 (Ang-1) and its naturally occurring antagonist angiopoietin-2 (Ang-2) specifically bind to Tie2/Tek receptors and are essential for normal vascular development (Maisonpierre et al, 1997; Suri et al, 1998). However, whereas Ang-1 causes Tie2/Tek phosphorylation in endothelial cells, Ang-2 does not. Rather it binds to Tie2/Tek receptors and blocks the action of Ang-1 (Maisonpierre et al, 1997). Thus, it has been postulated that the natural role of Ang-2 may be to 
antagonize Ang-1 activation of Tie2/Tek (Maisonpierre et al, 1997). Overexpression of Ang-2 in transgenic mouse embryos produces vascular deficits during development that are more severe than those seen in mice lacking Ang-1 or Tie2/Tek receptors (Davis et al, 1996; Dumont et al, 1994; Maisonpierre et al, 1997; Sato et al, 1995; Suri et al, 1998). By contrast, overexpression of Ang-1 results in increased vascularization (Suri et al, 1998), suggesting that angiopoietins play a critical role in regulating angiogenesis in vivo. However, addition of Ang-1 to endothelial cell cultures does not promote proliferation, as previously observed with other classic angiogenic growth factors (Davis et al, 1996), but can induce sprouting and branching in vitro (Davis et al, 1996; Koblizek et al, 1998; Papapetropoulos et al, 1999). Recently, Ang-1 was shown to prevent apoptosis of endothelial cells in vitro (Holash et al, 1999; Kwak et al, 1999; Papapetropoulos et al, 1999).

It has long been proposed that a tumor needs to produce new vessels to grow, and the richer this vascularization, the better the growth (Folkman, 1971; 1990). In this paper we report the identification of an early stage in glioma growth that has no morphological evidence of angiogenesis but involves the recruitment of normal cerebral vessels. Our results confirm previous reports (Holash et al, 1999) and indicate that, in contrast to the classical scheme of tumor growth in two phases (ie, avascular and vascular phases), the growth of gliomas actually progresses through two vascular phases. The first vascular phase is dependent upon native blood vessels that are parasitized by tumor cells. The second vascular phase is associated with angiogenesis, ie, neovascularization (the development of newly formed vessels). We also show that apoptosis of vascular cells in preexisting native vessels appears to be a transition step between the two phases. It plays a crucial role in the involution of the previously normal viable vessels, leading to tumor cell death followed by tumor necrosis and subsequent angiogenesis. Thus, glioma growth requires both apoptosis and angiogenesis. We have previously demonstrated that vascular cells in gliomas express Ang-2 (Holash et al, 1999; Zagzag et al, 1999). Because Ang-2 is an antagonist of Ang-1, which promotes endothelial cell survival (Holash et al, 1999; Kwak et al, 1999; Papapetropoulos et al, 1999), we wanted to further explore the association of Ang-2 expression with vascular cell apoptosis (Holash et al, 1999). We studied the sequential growth of an experimental glioma and compared the pattern of expression of Ang-2 and the distribution of apoptotic cells as determined by terminal deoxynucleotidyl transferasemediated biotinylated deoxyuridine triphosphate nick end labeling (TUNEL). Moreover, to better investigate vascular apoptosis, we performed transmission electron microscopy (TEM) in each step of the growth of the experimental glioma. Our findings suggest that expression of Ang-2, an antagonist of Ang-1, is associated in vivo with vascular cell apoptosis, which is linked to vascular involution.

\section{Results}

\section{Light and Fluorescence Examination}

Tumor progression was analyzed by light microscopy and detection of green fluorescent protein (GFP) labeled tumor cells. Remarkably, accumulation of tumor cells around existing vessels (Holash et al, 1999; Nagano et al, 1993) was observed even 1 week after injection of tumor cells (Fig. 1A). These tumors were just a fraction of a millimeter in width. At this stage, the vascular density of the tumors appeared similar to that of the host brain. After 2 weeks, tumors had grown to approximately $2 \mathrm{~mm}$ in diameter (Fig. 1B), and the tumor cells were primarily organized around native cerebral vessels. Because of the increase in the number of perivascular glioma cells, vessel density within the tumor actually seems to have decreased by this stage. These intratumoral vessels appear ectatic and distinctly larger than the microvasculature of the normal brain. After 3 weeks, there were focal zones of necrosis centered around a vascular ghost. After 4 weeks, extensive areas of necrosis with cuffs of pseudopalisading cells had developed and were surrounded by increased vascular density (Fig. 1, C and D). Angiogenesis was obvious at the margins of large tumors, where several newly formed blood vessels were present. Tumor cell invasion occurred both around vascular channels (Fig. 1D) and as individual infiltrating tumor cells easily detectable by the GFP label.

Thus, analysis of the tumors at 1 and 2 weeks after injection confirmed that they did not initially grow as avascular structures (Holash et al, 1999; Nagano et al, 1993), but instead the tumor cells rapidly targeted to and surrounded existing host vessels. The subsequent involution of native vessels results in multifocal necrosis of tumor cells that were dependent upon these vessels. This is followed in later stages of tumor growth by the onset of peripheral angiogenesis, which is associated with an increase in tumor size.

\section{Expression of Ang-2 in Experimental Gliomas}

Given the proposed role of Ang-2 in tumor angiogenesis (Holash et al, 1999; Maisonpierre et al, 1997; Zagzag et al, 1999), we were interested in analyzing its expression in this model. To explore the relationship between the temporal changes in tumor vasculature and the expression of Ang-2, we performed in situ hybridization analysis. Ang-2 was expressed in vascular cells as early as 1 week after tumor implantation (Fig. 2, A and B) only in vessels surrounded by tumor cells. These vessels were located primarily at the periphery of the tumor. After 2 weeks, blood vessels remained positive for Ang-2 (Fig. 2, C and D). After both 1 and 2 weeks, normal brain vessels not surrounded by tumor cells had no Ang-2 expression. After 3 (Fig. 2, E and F) and 4 (Fig. 2, G and H) weeks, expression of Ang-2 was seen, not only in cells of intratumoral vessels, but also in vessels at the tumor edge (Fig. 2G) where it was detected in vessels surrounded by tumor cells. This Ang-2 expression is 


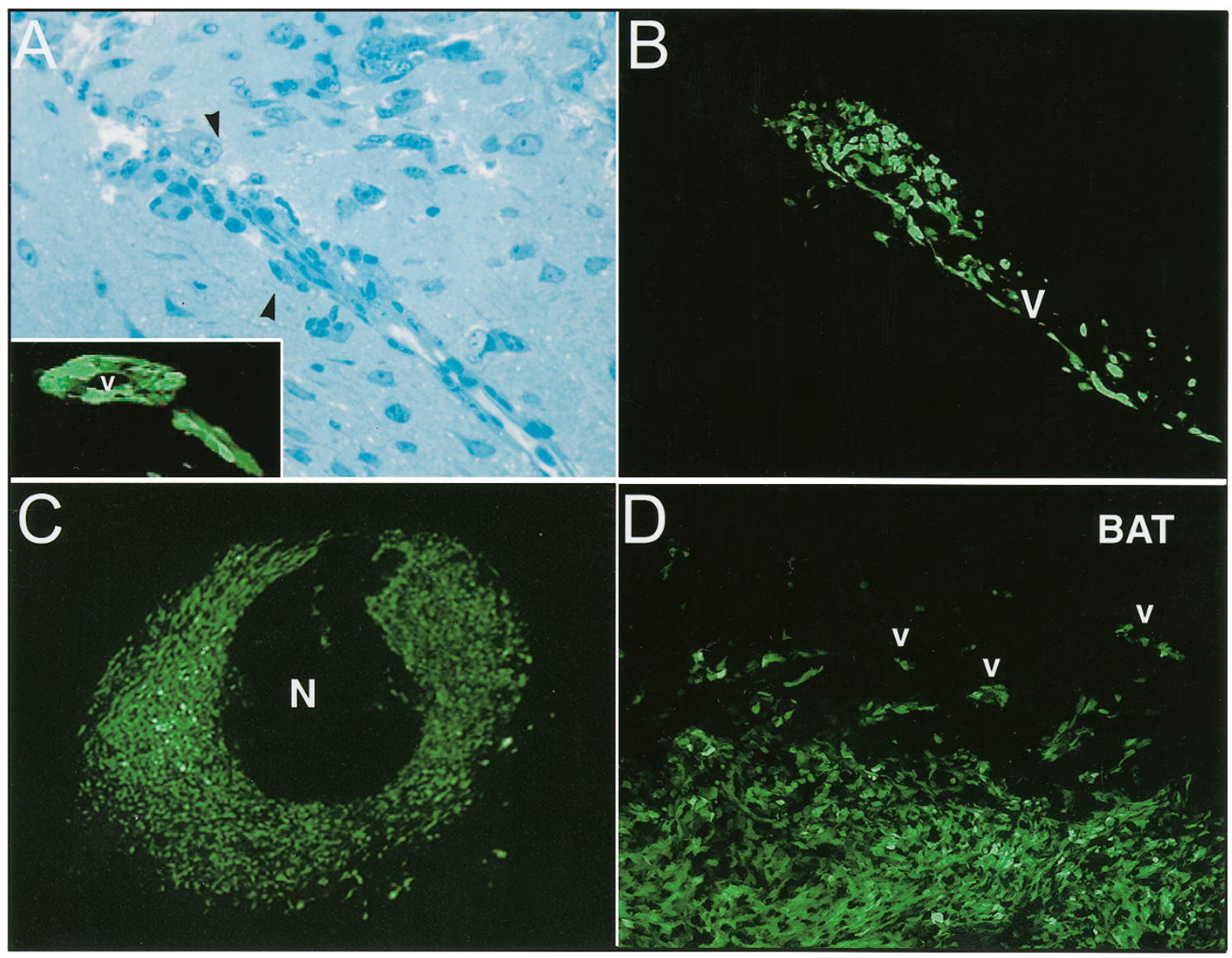

\section{Figure 1.}

Progression of the GL261 glioma. A, One week postinjection, Toluidine Blue already shows early perivascular organization of the tumor cells (arrowheads) ( $\times 200$ ) green fluorescent protein (GFP) labeled Glioma 261 tumor cells around a vascular channel (v) $(\times 100)$. B, By 2 weeks, the number of perivascular GFP-labeled tumor cells is increased $(\times 200)$. C , At 4 weeks, the necrotic center of the tumor $(\mathrm{N})$ fails to show green fluorescence. By contrast, the viable periphery of the tumor appears green $(\times 50)$. $D$, At the tumor edge, GFP-labeled tumor cells infiltrate the surrounding brain around vascular channels $(v)(\times 100)$.

consistent with that described in the rat C6 glioma (Holash et al, 1999), and it is an early and specific marker of both existing vessels that have been coopted by tumors and new vessels in advanced tumors that exhibit angiogenesis (Zagzag et al, 1999).

\section{TUNEL}

Apoptosis was detected in tissue sections by morphological criteria and TUNEL analysis of nuclear DNA fragmentation. After 1 week (Fig. 3A), there were no TUNEL-positive cells except for the rare cells in the injured cortex just adjacent to the injection site. Most commonly, single TUNEL-positive cells were interspersed among normal TUNEL-negative neurons in the cortex (data not shown). After 2 weeks (Fig. 3B), rare TUNEL-positive vascular cells were detectable in vessels surrounded by tumor cells. After 3 weeks (Fig. $3 C)$, numerous vascular cells were TUNEL-positive. Rare tumor cells also were stained (Fig. 3C). After 4 weeks (Fig. 3D), many more TUNEL-positive cells were present, including both vascular and tumor cells. Tumor cells demonstrated uneven TUNEL staining, predominantly in the cytoplasm, but the nuclei were also stained. These TUNEL-positive tumor cells lacked morphological features characteristic of apoptosis, such as cell shrinkage, nuclear condensation, or nuclear fragmentation. On the contrary, they displayed morphological features of necrotic cell death (Fig. 3D). In contrast, the TUNEL-positive vascular cells were round and shrunken with condensed nuclei, suggesting that these were undergoing an apopotic cell death.

\section{Transmission Electron Microscopy}

Some studies have suggested that the TUNEL method is not specific for apoptosis and may also label necrotic cells (Grasl-Kraupp et al, 1995). To identify more clearly the types of cells undergoing apoptosis and to better visualize vascular changes during tumor formation, we performed ultrastructural analysis by TEM. After 1 week, there were tumor cells surrounding blood vessels just adjacent to the vascular basement membrane that appeared to be "lifting up" the native astrocytic feet processes away from the vascular cells (Fig. 4, A and B). After 2 weeks, TEM showed closely packed perivascular proliferating tumor cells surrounding thin-walled vessels with no identifiable basement membrane (Fig. 4C). After 3 weeks, there were 


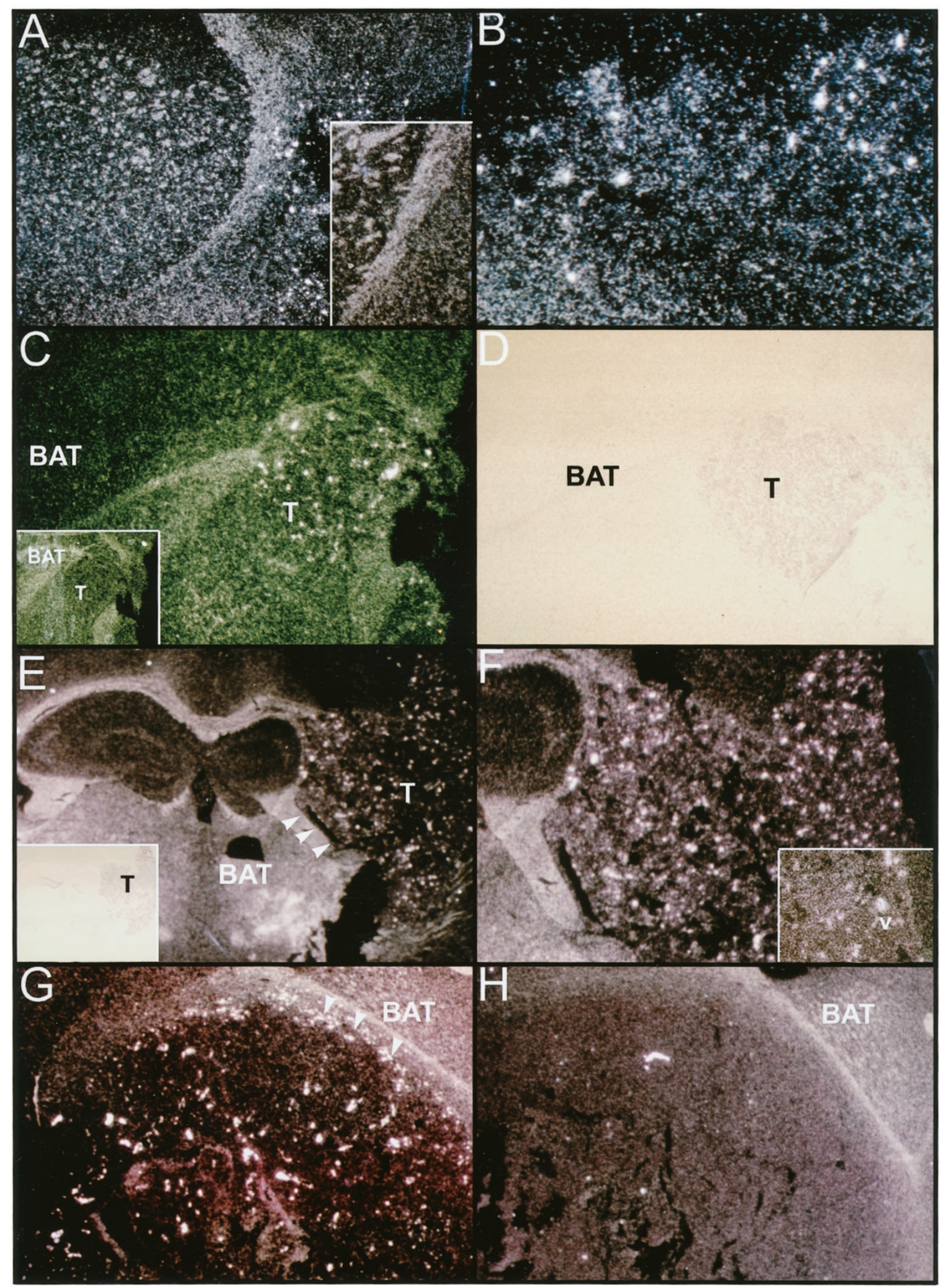

\section{Figure 2.}

In situ hybridization for Ang 2 mRNA in the GL261 Glioma. A, At 1 week, early and strong Ang-2 expression is seen with the antisense probe as demonstrated by bright fluorescence $(\times 40)$. Inset: No signal can be detected with the sense probe $(\times 40)$. B. Higher magnification of panel $A(\times 100)$. C, Intratumoral $(T)$ vessels are labeled with the antisense Ang-2 probe. There is no staining in the brain adjacent to the tumor (BAT). Tumor cells are not stained $(\times 20)$. Inset: No staining was detected with the sense probe on a section adjacent to that shown in panel $C(\times 5)$. D, Phase microscopy shows tumor $(T)$ and BAT $(\times 20)$. E, 3 weeks tumor $(T)$. Tumor borders appear well delineated (arrowheads) against the surrounding BAT $(\times 12.5)$. Inset: Phase microscopy shows tumor $(T)(\times 5)$. $F$, Higher magnification of panel $E(\times 40)$. Inset: Vascular forms with hollow center $(V)$ are observed $(\times 40)$. G, Some intratumoral vessels show Ang-2 expression. In addition, newly formed blood vessels at the periphery are strongly positive for Ang-2 (arrowheads) $(\times 20)$. H, No staining is seen with the sense probe $(\times 20)$. 


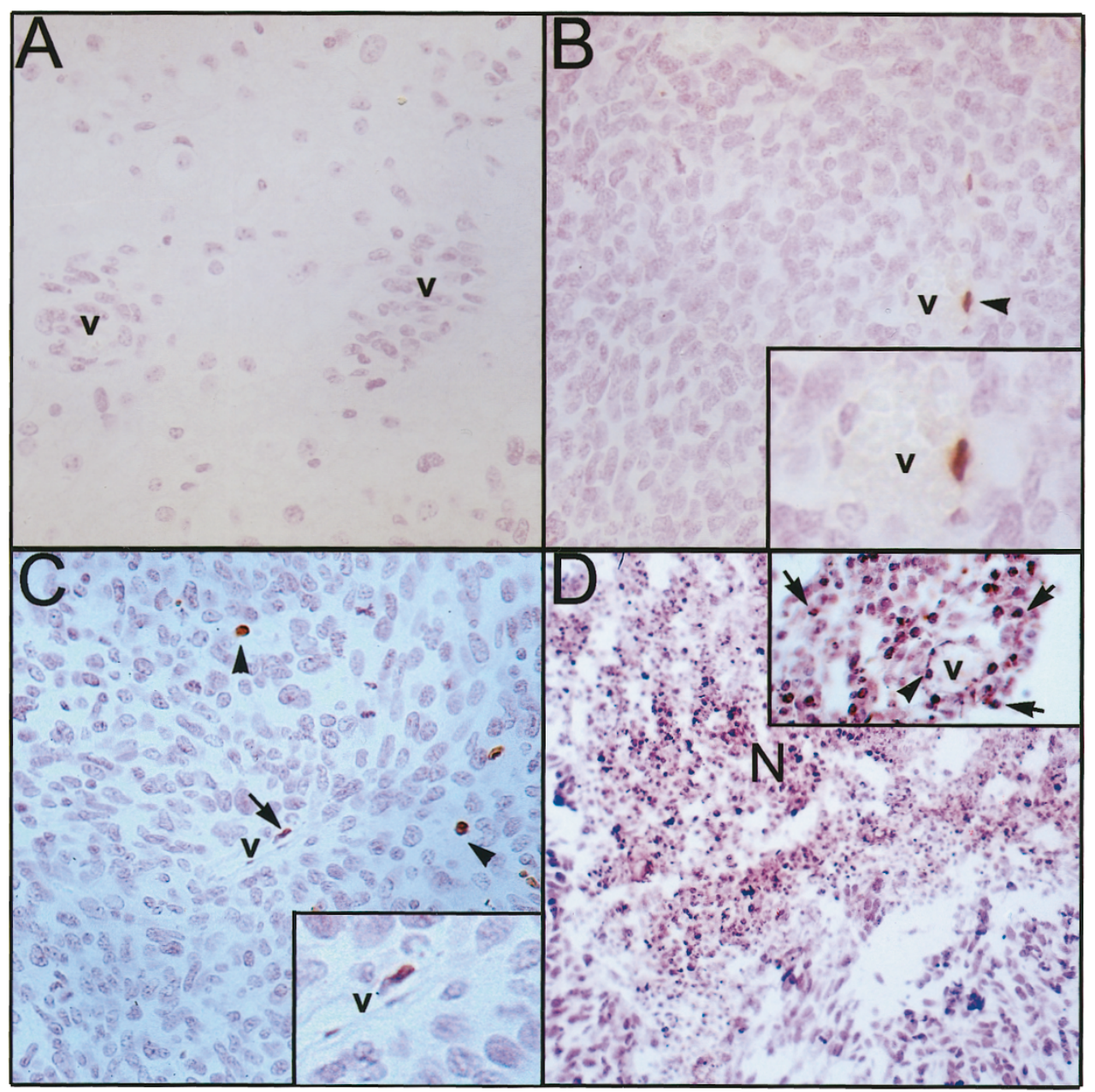

\section{Figure 3.}

TUNEL assay. A, At 1 week postinjection, no TUNEL-labeled vascular (v) or tumor cells are detected (×200). B, By 2 weeks, TUNEL-positive vascular cells $(v)$ are seen (arrowhead) ( $\times 100)$. Inset: Higher magnification showing the labeled vascular cell; adjacent unstained intravascular red blood cells are recognized $(\times 400)$. $C$, By 3 weeks, vascular cells (v) (arrow) and tumor cells (arrowheads) are immunolabeled $(\times 100)$. Inset: Higher magnification showing the labeled vascular cell $(\times 400)$. $D$, By 4 weeks, extensive labeling of dead tumor cells is seen in a necrotic zone (N) $(\times 50)$. Inset: Both vascular cells (v) (arrowheads) and tumor cells (arrows) are seen ( $\times 100)$.

occasional pericytes with features of apoptosis (Fig. 4, $D$ and E). These cells demonstrated shrinkage, increased cytosolic densities, vacuolization, and condensed nuclear chromatin. The cytoplasm of apoptotic cells also contained small ultracondensed mitochondria and small vesicles. Fully apoptotic endothelial cells were not seen. However, condensed mitochondria, clumps of partially condensed chromatin dispersed throughout the nucleoplasm, or perinuclear clumping of condensed chromatin, were detected in occasional endothelial cells without other morphological signs of apoptosis (Fig. 4, F and G). Intraluminal cells with features similar to those described in apoptotic pericytes were seen in some vessels. These might represent apoptotic endothelial cells detached from the vascular wall. At this time, the tumor continued to show numerous apoptotic cells and apoptotic bodies; however, tumor cells adjacent to vessels with apoptotic vascular cells always lacked the morphological changes of apoptosis. After 4 weeks, necrotic tumor cells were seen surrounding nonviable blood vessels where the red blood cells were contained by the remaining framework of the dead vessels (Fig. 4H).

\section{Correlation of Ang-2 Signal and TUNEL}

Given that Ang-2 is an antagonist of Ang-1, an endothelial cell survival factor (Holash et al, 1999; Kwak et al, 1999; Papapetropoulos et al, 1999), we investigated the possible correlation between the distribution of apoptotic cells and the expression of Ang-2 in our experimental gliomas. It was of interest to compare the distribution of Ang-2 with TUNEL-positive cells within the tumor. After 1 week, Ang-2 expression was evident in some affected vessels with no evidence of TUNEL-positive vascular cells. After 2 weeks, Ang-2 had increased in vessels, and an initial indication of TUNEL positivity in vascular cells was observed. A comparison, using TEM, of Ang-2 expression with the distribution of TUNEL-positive cells and apoptotic cells revealed that Ang-2 signals were observed before or simultaneously with the development of TUNEL positivity in individual vascular cells. Overall, there was 

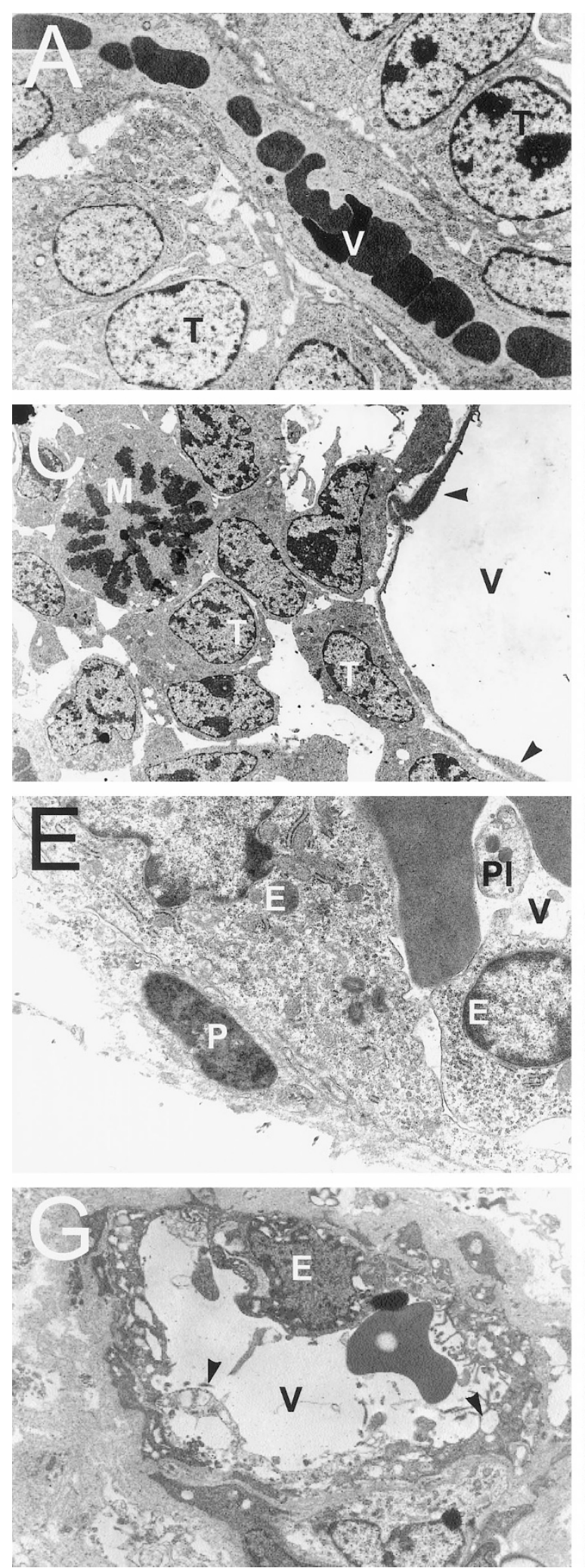
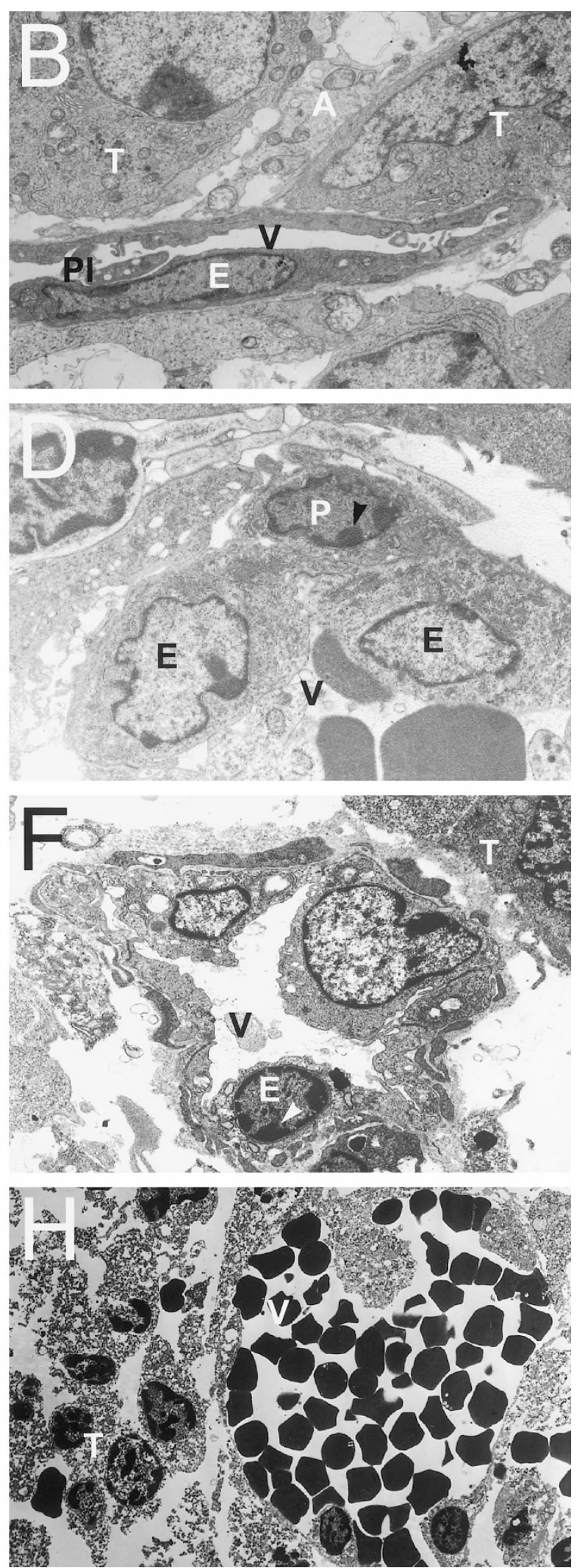

Figure 4.

Ultrastructural changes in vascular involution. $A$, At 1 week, tumor cells $(T)$ adjacent to a viable blood vessel $(V)(\times 2000)$. B, Tumor cells $(T)$ approximate the blood vessel apparently lifting the native astrocytic processes $(A)(\times 4000)(\mathrm{V}$ : blood vessel; E: endothelial cell; Pl: platelet). C, At 2 weeks, proliferating tumor cells $(\mathrm{T})$ expand the perivascular neoplastic "cuffing." The vessel $(\mathrm{V})$ is lined by "flat" endothelial cells (arrowheads) and lacks basement membrane $(\mathrm{M}$ : mitosis) $(\times 2000)$. $D$, At 3 weeks, pericyte (P) with condensed chromatin (arrowhead) and cytoplasm is seen in a still viable blood vessel (V) (E: endothelial cells) $(\times 3150)$. E, A fully apoptotic pericyte (P) is seen in a vessel $(V)$ with viable endothelial cells $(E)$ (PI: platelet) $(\times 4000)$. F, A single endothelial cell $(E)$ with condensed chromatin (arrowhead) and mitochondria is seen in a vessel (V) with no other signs of apoptosis (T: tumor cells) $(\times 4000)$. G, A vessel (V) showing an endothelial cell (E) with condensed chromatin and cytoplasm. Other endothelial cells showed marked cytoplasmic vacuolization (arrowheads) $(\times 2500)$. H, At 4 weeks, necrotic vessel $(V)$ surrounded by nonviable tumor cells $(\mathrm{T})(\times 1250)$. 
good correlation of in situ hybridization signal for Ang-2 and TUNEL immunoreactivity. We observed up-regulation of Ang-2 in vessels that lacked morphological evidence of hyperplasia, including a lack of plump endothelial cells. In addition, many vessels exhibited TUNEL staining and displayed Ang-2 signal in endothelial cells. These observations suggest that the enhanced expression of Ang-2 in vascular cells preceded, or coincides with, vascular apoptosis and involution, and could be responsible for it.

\section{Discussion}

\section{Vascular Involution and Tumor Necrosis Follows Perivascular Tumor Cell Homing: A Novel Concept for Glioma Growth}

In recent years, the essential role played by angiogenesis in neoplastic growth has been carefully investigated. The hypothesis that tumor growth is dependent on angiogenesis postulates that tumor growth must be preceded by an increase in new capillaries and that tumors go through an avascular phase in which they do not become larger than 1 or $2 \mathrm{~mm}$ (Folkman, 1971; Folkman, 1990). Our study demonstrates that glioma growth goes through two vascular phases and shows that tumor necrosis follows involution of parasitized native vessels, mediated, at least in part, by vascular cell apoptosis. This study and previous studies (Holash et al, 1999) have led us to propose a five-stage sequence to explain brain tumor progression (Fig. 5): (a) implantation, (b) perivascular organization, (c) proliferation, (d) vascular involution associated with vascular cell apoptosis, and (e) tumor necrosis and hypoxia leading to angiogenesis.

In the very early stages of neoplastic growth, just after implantation, glioma cells are scattered in the neuropil, followed by early perivascular organization around existing cerebral vessels. In our experiments, GL261 glioma cells are not implanted around blood vessels, yet 1 week after inoculation, the tumor cells are distributed preferentially around vessels. This suggests an active homing of the tumor cells to the native cerebral vessels as was described in the rat C6 glioma (Holash et al, 1999; Nagano et al, 1993). The mechanisms responsible for this vasculotropic process and preferential perivascular growth (Nicosia et al, 1983; 1986) are unknown. After the initial perivascular tumor distribution and further tumor cell proliferation, vascular involution of these native vessels leads to tumor hypoxia. This is associated with vascular apoptosis and could be linked with Ang-2 expression. This in turn leads to neovascularization in the advanced stages of growth. This angiogenesis is likely to be mediated by vascular endothelial growth factor (VEGF) that is expressed by hypoxic cells after regression of preexisting cerebral vessels (Holash et al, 1999). Similarly in human gliomas, VEGF is typically expressed in pseudopalisading hypoxic zones around areas of necrosis that are adjacent to hyperplastic vessels (Plate et al, 1992; Shweiki et al, 1992).

Thus, the main difference between these two vascular phases is that in the first, the vessels are native cerebral vessels that are parasitized by tumor cells. In contrast, in the second phase there is formation of new blood vessels, mostly at the tumor periphery, which arise from existing vessels. This novel concept (Holash et al, 1999) suggests that in richly vascularized organs, eg, brain (Holash et al, 1999), lung (Pezzella et al, 1997), or tongue (Leedy et al, 1994), tumors can obtain an efficient blood supply from a suitable native vascular bed (eg, cerebral blood vessels). Pre-existing vessels are able to temporarily provide essential blood supply for tumor progression. These pre-existing parasitized vessels fail to undergo angiogenesis, but instead, involute. This in turn leads to tumor necrosis, and eventually angiogenesis occurs. By contrast, in avascular organs, such as the cervix (Smith-McCune and Weidner, 1994), or in experimental assays such as corneal pocket assay (Gimbrone et al, 1974), tumors have an initial avascular phase, followed by neovascularization. Thus, tumors may grow following one of these two pathways, depending on the organ.

\section{Vascular Involution Is an Important Step in the Chain of Events Leading to Glioma Growth and Appears to Be, at Least in Part, Mediated by Vascular Cell Apoptosis}

Apoptotic cells were variably detected in vascular channels. Apoptosis, a highly ordered, programmed cell death, leads to fragmentation of dying cells into apoptotic bodies that are phagocytosed by neighboring cells or macrophages (Wyllie et al, 1980). It is characterized by structural changes including mitochondrial condensation, cell shrinkage, plasma membrane blebbing, chromatin condensation and aggregation, and cytoskeletal disruption (Wyllie et al, 1980), as well as by biochemical changes including activation of caspases (Alnemri et al, 1996; Granville et al, 1999).

Morphologic changes observed in the vascular smooth muscle, pericytic, and endothelial cells were typical of apoptosis, including chromatin condensation and ultracondensed mitochondria (Allen et al, 1998; Dinsdale et al, 1999; Payne et al, 1995). Smooth muscle and endothelial cell apoptosis have been shown to play an important role in vascular regression in physiological and pathological processes (Bennet and Boyle, 1998; deBlois et al, 1997; Goede et al, 1998; Honma and Hamasaki, 1998; Modlich et al, 1996; Shabisgh et al, 1999; Walker and Gobe, 1987; Walker et al, 1989). For example, there is increasing evidence showing that vascular smooth muscle cell apoptosis is involved in the pathogenesis of atherosclerosis and restenosis following angioplasty (Bennet and Boyle, 1998). Similarly, endothelial cell apoptosis has been described in regression of the ovarian corpus luteum (Azmi and O'Shea, 1984; Goede et al, 1998; Modlich et al, 1996), salivary gland atrophy by duct occlusion (Walker and Gobe, 1987), involution of the lactating breast after weaning (Walker et al, 1989), scar formation after wound healing (Desmouliere et al, 1995), involution of foreign body granuloma (Honma and Hamasaki, 1998), and prostatic involution after castration (Shabisgh et al, 1999). Of interest, endothe- 


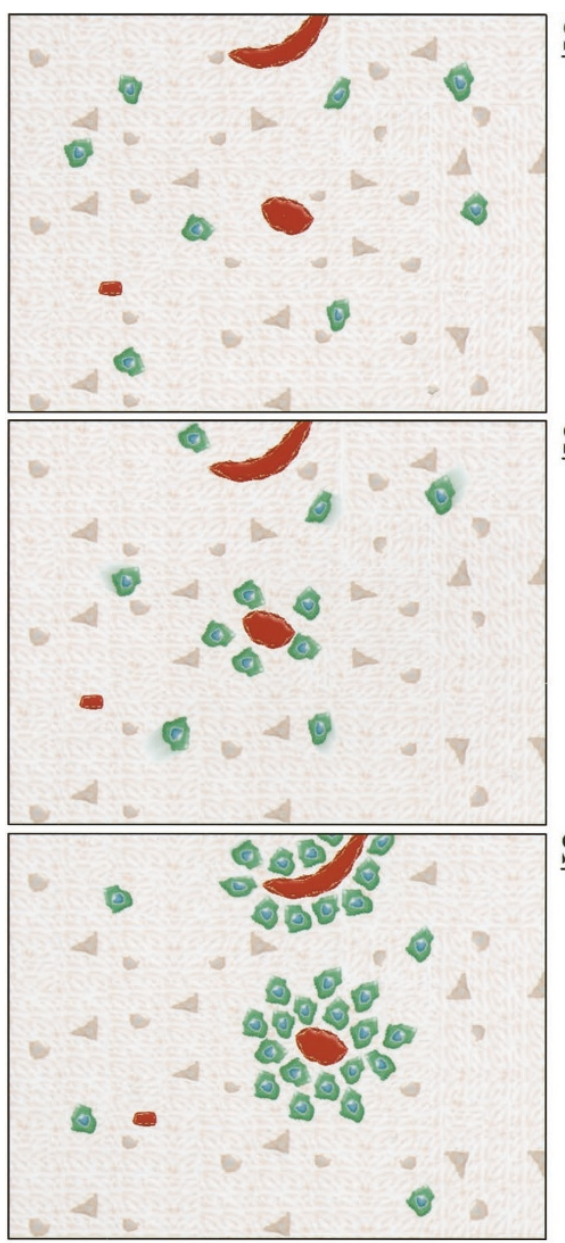

Stage I

Implantation

Stage II: Week 1

Perivascular

Organization

\section{Stage III : Week 2}

Proliferation

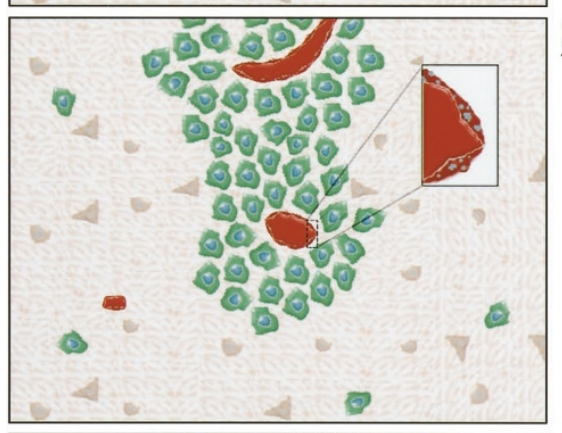

Stage IV: Week 3

Apoptosis and

Involution

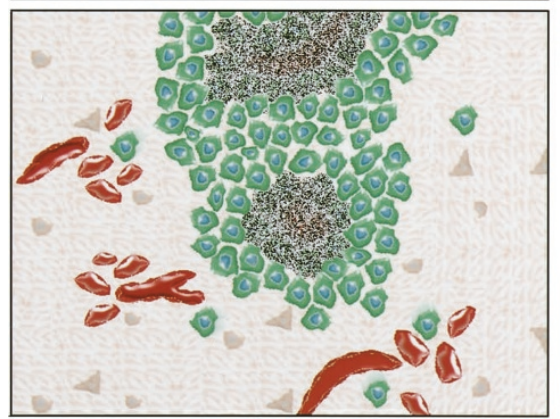

Stage V: Week 4

Angiogenesis

\section{Legend}

- Tumor cells $\Delta$ Neurons

- Vessels Oligos

\section{Figure 5.}

Five stages of GL261 growth in the brain. Stage I: Implantation. This is the initial phase just after tumor cell inoculation. The tumor cells are dispersed within the neuropil. Stage II: Perivascular Organization (Week 1). The tumor cells are concentrated around nutrient-rich native blood vessels. Stage III: Proliferation (Week 2). The tumor cells proliferate around the still viable blood vessels. Stage IV: Apoptosis and Involution (Week 3). Apoptosis in vascular cells occurs and degeneration of the blood vessels becomes evident. The involution of the host vessels is likely to lead to hypoxia, which in turn will induce VEGF release, leading to angiogenesis. Inset: Apoptic bodies are seen in endothelial cells. Stage V: Angiogenesis (Week 4). Neovascularization occurs as blood vessels grow toward and vascularize the now necrosing tumor (central gray stippled area), providing a new source of nutrition. 
lial cell apoptosis has been recently reported in central nervous system lymphomas (Molnar et al, 1999).

\section{Tumor-Vascular Cell Contact Appears to Be Crucial in Inducing Vascular Cell Apoptosis}

Mechanisms regulating vascular apoptosis have been only partially elucidated. Apoptotic death of vascular cells results from transduction of death signals triggered by various exogenous stimuli including (a) cytokines, eg, tumor necrosis factor- $\alpha$ (TNF $\alpha$ ) (Geng et al, 1996; Robaye et al, 1991); (b) Fas/Fas ligand signaling (Kagi et al, 1994; Nagata, 1997); (c) loss of extracellular matrix (ECM) contacts (anoikis) (Bates et al, 1994; Frisch and Francis, 1994; Re et al, 1994; Ruoslahti and Reed, 1994); (d) hypoxia (Stempien-Otero et al, 1999) and reactive oxygen species (Kayanoki et al, 1996; Li et al, 1997); and (e) withdrawal of a trophic factor, eg, bFGF (Fox and Shanley, 1996) or VEGF (Benjamin et al, 1999; Benjamin and Keshet, 1997). Cytokines released by glioma cells (Zagzag, 1995), eg, TNF- $\alpha$ (Geng et al, 1998; Robaye et al, 1991) and TGF- $\beta$ (Pollman et al, 1996), are able to cause apoptosis of endothelial and smooth muscle cells. By contrast, conditioned media from glioma cells have an opposite, growth-promoting effect on endothelial cells (Kelly et al, 1976; Shweiki et al, 1992; Zagzag, 1995). Conditioned media from breast adenocarcinoma cells fail to affect endothelial cell integrity and viability (Kebers et al, 1998), whereas endothelial cells undergo apoptosis when contacted by adenocarcinoma cells, ie, apoptotic endothelial cells are mostly observed in the vicinity of tumor cells (Kebers et al, 1998). Similarly, in developmentally programmed capillary regression, endothelial cell apoptosis is dependent on contact with macrophages (Meeson et al, 1996). Moreover, membrane-bound Fas ligand induces apoptosis (Nagata, 1997), but soluble Fas ligand binding to Fas-bearing endothelial cells does not (Richardson et al, 1994), further reinforcing the importance of cell to cell contact for the induction of apoptosis. Fas ligand is expressed in glioblastomas, whereas Fas is observed diffusely in the microvasculature within the central nervous system (Leithauser et al, 1993; Tohma et al, 1998). In our glioma model, as early as 7 days after tumor inoculation, close contact between glioma and vascular cells results in the lifting up of astrocytic foot processes by tumor cells. This represents an early disruption of endothelial integrity by disrupting endothelial cell-matrix interactions of the perivascular matrix, which has been shown to play an important role in endothelial cell survival (Nicosia et al, 1986) and in angiogenesis (Nicosia and Madri, 1987). Endothelial cells rapidly undergo apoptosis when denied proper substrate adhesion, ie, in the absence of interactions with ECM (Re et al, 1994; Ruoslahti and Reed, 1994). This form of programmed cell death, induced when cell attachment to a substratum is disrupted, has been termed anoikis (Frisch and Francis, 1994; Frisch and Ruoslahti, 1997). ECM-cell interactions are mediated to a large extent by the integrins (Hynes, 1992; Ruoslahti, 1996; Yamada and Miyamoto, 1995). Among critical biological functions, integrins have been shown to serve as a survival mechanism in several anchorage-dependent cell types. For example, an antagonist of $\alpha \mathrm{v} \beta 3$ integrin mediates regression of tumor vessels via apoptosis (Brooks et al, 1994). The mechanism by which integrin-mediated adhesion suppresses anoikis in these cell types, however, remains unclear. Focal adhesion kinase (FAK), which is known to bind and mediate integrin-dependent signals (Schaller et al, 1992), has been shown to be required for adhesion and survival of both nontransformed cells (Frisch et al, 1996; Hungerford et al, 1996) and tumor cells (Xu et al, 1996). For example, decreased FAK expression results in apoptosis (Xu et al, 1996), whereas FAK expression suppresses apoptosis (Frisch and Ruoslahti, 1997). Moreover, estrogeninduced inhibition of endothelial cell apoptosis in vitro is associated with tyrosine phosphorylation of FAK (Alvarez et al, 1997).

\section{Is ANG-2 an Apoptosis Inducing Agent Related to Its Ang-1 Antagonistic Effects?}

Addition of Ang-1 to endothelial cell cultures prevents apoptosis (Holash et al, 1999; Kwak et al, 1999; Papapetropoulos et al, 1999). It has been postulated that the natural role of Ang-2 may be to antagonize Ang-1 activation of Tie2/Tek, an endothelial-cellspecific tyrosine kinase receptor. Thus, the blocking of the effect of the Ang-1 survival agent (Holash et al, 1999; Kwak et al, 1999; Papapetropoulos et al, 1999) could be a key factor for vascular cell apoptosis. By contrast to Ang-1, which causes Tie2/Tek phosphorylation in endothelial cells, its natural antagonist, Ang-2, which also binds to Tie2/Tek, does not, and it blocks the action of Ang-1 (Maisonpierre et al, 1997). Ang-2 up-regulation has been demonstrated in the regression of the ovarian corpus luteum (Maisonpierre et al, 1997), which has been linked to blood vessel involution associated with vascular cell apoptosis (Azmi and O'Shea, 1984; Goede et al, 1998; Modlich et al, 1996). Our data indicate that vascular cell apoptosis, as assessed by TUNEL labeling and TEM, follows expression of Ang-2 in vivo, suggesting that Ang-2 is a potential inducer of apoptosis in vascular cells in vivo. In the C6 glioma rat model (Holash et al, 1999) and in human gliomas (Zagzag et al, 1999), a similar pattern of Ang-2 expression was observed in tumor-associated vessels. Our results support the hypothesis that, in the pressure of low levels or in the absence of VEGF, Ang-2 inhibits constitutive Ang-1 signal and promotes vascular cell demise (Holash et al, 1999; Maisonpierre et al, 1997; Zagzag et al, 1999). By contrast, when VEGF, an endothelial cell survival factor (Benjamin et al, 1999; Mitchell et al, 1998) that induces Bcl-2 expression (Nor et al, 1999) and FAK phosphorylation (Abedi and Zachary, 1997), is present, endothelial cells proliferate and survive (Alon et al, 1995; Benjamin et al, 1999; Benjamin and Keshet, 1997; Mitchell et al, 1998; Nor et al, 1999). In addition, newly deposited ECM molecules, eg, tenascin- $C$, which promotes survival of smooth mus- 
cle cells (Jones et al, 1997), are overexpressed in angiogenic vessels of astrocytomas (Zagzag et al, 1996) and could contribute to the prevention of apoptosis. Essentially, in the early stages of glioma progression, vascular cell death occurs after tumor cells disrupt the contact of the vascular cell microenvironment whereas vascular cell survival is identified in the more advanced stages of tumor growth when VEGF and ECM proteins are abundant.

The mechanisms that initiate apoptotic stimuli are unknown, but it is likely that more than one stimulus/ initiator may exist. Several of the potential mechanisms described above could be associated with vascular cell apoptosis, resulting in a complex in vivo interplay that needs to be explored. For example, glioma cells may contribute to vascular cell apoptosis in various ways: by interrupting ECM contact, by presenting membrane bound Fas ligand to Fas on vascular cells, or by up-regulating Ang-2. In addition, the effects of cytokines such as TGF- $\beta$ on vascular cells is modulated by cell-matrix interactions and serum (Pollman et al, 1996).

In summary, we have evidence suggesting that glioma growth goes through two vascular phases. Early Ang-2 expression in vascular channels of gliomas, in the absence of VEGF (Holash et al, 1999), precedes vascular involution and may play an important role in initiating vascular cell apoptosis. Further studies are needed (a) to determine the molecular mechanisms that cause tumor cells to home to existing blood vessels; (b) to discover the factors responsible for the up-regulation of Ang-2; and (c) to investigate the molecular mechanisms underlying the possible apoptotic effect of Ang-2. These experiments will help to elucidate the molecular processes involved in brain tumor apoptosis, angiogenesis, and progression.

\section{Materials and Methods}

\section{GL261 Glioma Model}

GL 261 glioma cells were implanted in the brain of 28 C57BL6 mice (Akbasak et al, 1991). The mice were placed in the Kopf rodent stereotactic apparatus (Tujunga, California). After sterilization, a 1-cm-long scalp incision was made. A burr hole was placed at the stereotactically defined location of the caudate/putamen, $0.1 \mathrm{~mm}$ posterior to the bregma, $2.32 \mathrm{~mm}$ lateral to the midline (Franklin and Paxinos, 1997). A Hamilton syringe (Reno, Nevada) was advanced to a depth of $2.35 \mathrm{~mm}$ from the cortical surface, and $4 \mu \mathrm{l}$ of Ham's F12 medium containing $1 \times 10^{5}$ GL261 glioma cells was injected. To facilitate cell identification, the GL261 glioma cells had previously been transfected with the gene for green fluorescent protein (GFP), using a plasmid obtained from Clontech (Palo Alto, California) (Chishima et al, 1997; Gubin et al, 1997). We found that nearly all of the tumor cells exhibited green fluorescence in vitro and that they could be easily visualized following transplantation in vivo. Seven animals were killed each week, for 4 weeks. Before they were killed, the animals were anesthetized and then perfused through the heart with phosphate buffered saline (PBS) followed by $4 \%$ paraformaldehyde. The brains were sectioned in the coronal plane to identify grossly detectable tumors. The tissues were fixed in $2 \%$ paraformaldehyde, sucrose protected, and then frozen until sectioning for in situ hybridization and fluorescence examination. Alternatively, tissues were fixed in glutaraldehyde for ultrastructural analysis or were embedded in paraffin and sectioned for microscopic examination. Hematoxylin and eosin (H\&E) stained sections revealed areas of necrosis, neovascularization, nuclear pleomorphism, many mitotic figures, and pseudopalisading around areas of necrosis, recapitulating essentially all of the pathologic features of human glioblastomas (Burger et al, 1985).

\section{In Situ Hybridization Analysis for Ang-2}

Frozen sections of tumor-containing cryoprotected mouse brains were probed with ${ }^{35} \mathrm{~S}$-labeled cRNAs as previously described (Holash et al, 1999; Maisonpierre et al, 1997; Valenzuela et al, 1993). The probe was a 680-nucleotide (nt) cRNA extending from the $5^{\prime}$ leader sequence at codon 155 in the mouse Ang-2 cDNA (Maisonpierre et al, 1997). Sections were immersed in radiographic emulsion (NTB-1; Kodak, Rochester, New York) and exposed for 14 to 21 days.

\section{TUNEL Assay}

TUNEL histochemistry was performed as described previously (Gavrieli et al, 1992). Briefly, 6- $\mu \mathrm{m}$-thick serial sections were cut from paraffin blocks of tumorbearing brains, affixed to slides by heating at $60{ }^{\circ} \mathrm{C}$ for 15 minutes, deparaffinized, and rehydrated. After digestion with $0.02 \%$ trypsin in phosphate-buffered saline (PBS) at room temperature and extensive washes in PBS, the sections were incubated in buffer A (200 mm Tris, $0.25 \mathrm{mg} / \mathrm{ml}$ bovine serum albumin, $\mathrm{pH}$ 6.6) for 5 minutes. The sections were then incubated with the labeling solution containing TdT $(0.3 \mathrm{U} / \mu \mathrm{l})$ (Boehringer Mannheim, Indianapolis, Indiana), biotinylated -16 dUTP (20 $\mu \mathrm{mol} / \mathrm{L}$, Boehringer Mannheim), and $1.5 \mathrm{~mm}$ chloride in buffer $\mathrm{A}$ at $37{ }^{\circ} \mathrm{C}$ for 60 minutes. The reactions were terminated by rinsing in buffer B (300 mM sodium chloride at $30 \mathrm{mM}$ sodium citrate, $\mathrm{pH} 7)$. The sections were then washed with $0.01 \mathrm{mM}$ Tris buffer, $\mathrm{pH} 7.5$, and blocked with $10 \%$ goat serum in $0.01 \mathrm{mM}$ Tris buffer for 15 minutes. For light microscopy, the labeled DNA fragments were visualized by incubating the sections in a 1/40 dilution of streptavidin-conjugated diaminobenzidine (BioGenex, San Ramon, California), followed by reaction with medium containing fast red as chromogen (Sigma Fast Kit; Sigma Chemical Company, St. Louis, Missouri). The slides were then washed, counterstained, and mounted in an aqueous medium.

\section{Transmission Electron Microscopy}

Samples of approximately $1 \mathrm{~mm}^{3}$ were cut from each tumor and fixed overnight in $3 \%$ glutaraldehyde at 4 
${ }^{\circ} \mathrm{C}$. Samples were postfixed with $1 \% \mathrm{OsO}_{4}$ in sodium cacodylate trihydrate at room temperature for 1 hour, dehydrated in a graded series of ethanols, and embedded in Eponate 12 resin (Ted Pella Inc, Redding, California). Sections (1- $\mu \mathrm{m}$-thick) were cut, and after selection of the most appropriate areas, ultrathin sections were cut with a diamond knife and counterstained with uranyl acetate and lead citrate. The sections were examined with a Zeiss EM 10 transmission electron microscope operated at 60KV.

\section{Acknowledgements}

This work was supported in part by a grant from the Children's Brain Tumor Foundation (to DZ). The authors wish to acknowledge the help of Drs. David Friedlander and Bronya Schiff. We thank Dr. Douglas C. Miller for his constructive comments, Luis Chiriboga and Judith Grecay for their expert technical assistance, and Stephanie Bruegman and Daniella Asaro for their help in the preparation of the manuscript.

\section{References}

Abedi H and Zachary I (1997). Vascular endothelial growth factor stimulates tyrosine phosphorylation and recruitment to new focal adhesion kinase and paxillin in endothelial cells. J Biol Chem 272:15442-15451.

Akbasak A, Olderfield SH, and Saris SC (1991). Expression and modulation of major histocompatability antigens on primary brain tumor in vitro. J Neurosurg 75:922-929.

Allen RT, Hunter WJ III, and Agrawal DK (1998). Morphologic and temporal analysis of vascular smooth muscle cell apoptosis induced by c-myc and E1A. Scanning 20:577-586.

Alnemri ES, Livingston DJ, Nicholson DW, Salvesen G, Thornberry NA, Wong WW, and Yuan J (1996). Human ICE/CED-3 protease nomenclature. Cell 87:171.

Alon T, Hemo I, Itin A, Peer J, Stone J, and Keshet E (1995). Vascular endothelial growth factor acts as a survival factor for newly formed retinal vessels and has implications for retinopathy of prematurity. Nat Med 1:1024-1028.

Alvarez RJ, Gips SJ, Moldovan N, Wilhide CC, Milliken EE, Hoang AT, Hurban RH, Silverman HS, Dang CV, and Goldschmidt-Clermont PJ (1997). 17beta-estradiol inhibits apoptosis of endothelial cells. Biochem Biophys Res Commun 237:372-381.

Azmi TI and O'Shea JD (1984). Mechanism of deletion of endothelial cells during regression of the corpus luteum. Lab Invest 51:206-217.

Bates RC, Buret A, van Helden DF, Horton MA, and Burns GF (1994). Apoptosis induced by inhibition of intercellular contact. J Cell Biol 125:403-415.

Benjamin LE, Golijanin D, Itin A, Pode D, and Keshet E (1999). Selective ablation of immature blood vessels in established human tumors follows vascular endothelial growth factor withdrawal. J Clin Invest 103:159-165.

Benjamin LE and Keshet E (1997). Conditional switching of vascular endothelial growth factor (VEGF) in tumors: Induction of endothelial cell shedding and regression of hemangioblastoma-like vessels by VEGF withdrawal. Proc Natl Acad Sci USA 94:8761-8766.
Bennet MR and Boyle JJ (1998). Apoptosis of vascular smooth muscle cells in atherosclerosis. Atherosclerosis 138: 3-9.

Brooks PC, Montgomery AMP, Rosenfeld M, Reisfeld RA, Hu T, Klier G, and Cheresh DA (1994). Integrin alpha v beta 3 antagonists promote tumor regression by inducing apoptosis angiogenic blood vessels. Cell 79:1157-1164.

Burger PC, Vogel FS, Green SB, and Strike TA (1985). Glioblastoma multiforme and anaplastic astrocytoma: Pathologic criteria and prognostic implications. Cancer 56:11061111.

Chishima T, Moyagi Y, Wang X, Yamaoka H, Shimada $H$, Moossa AR, and Hoffman RM (1997). Cancer invasion and micrometastasis visualized in live tissue by green fluorescent protein expression. Cancer Res 57:2042-2047.

Davis S, Aldrich TH, Jones PF, Acheson A, Compton LD, Jain V, Ryan TE, Bruno J, Radziejewski C, Maisonpierre PC, and Yancopoulous GD (1996). Isolation of angiopoietin-1, a ligand for the TIE2 receptor, by secretion-trap expression cloning. Cell 87:1161-1169.

deBlois D, Tea BS, Than VD, Tremblay J, and Hamet $\mathrm{P}$ (1997). Smooth muscle apoptosis during vascular regression in spontaneously hypertensive rats. Hypertension 29:340349.

Desmouliere A, Redard M, Darby I, and Gabbiani G (1995). Apoptosis mediates the decrease in cellularity during the transition between granulation tissue and scar. Am J Pathol 146:56-66.

Dinsdale D, Zhuang J, and Cohen GM (1999). Redistribution of cytochrome c precedes the caspase-dependent formation of ultracondensed mitochondria, with a reduced inner membrane potential, in apoptotic monocytes. Am J Pathol 155: 607-618.

Dumont DJ, Gradwohl G, Fong GH, Puri MC, Gertsenstein M, Auerbach A, and Breitman ML (1994). Dominant-negative and targeted null mutations in the endothelial receptor tyrosine kinase, tek, reveal a critical role in vasculogenesis of the embryo. Genes Dev 8:1897-1909.

Folkman J (1971). Tumor Angiogenesis: Therapeutic implications. N Engl J Med 285:1182-1186.

Folkman $J$ (1990). What is the evidence that tumors are angiogenesis dependent? J Natl Cancer Inst 82:4-6.

Folkman J (1995). Angiogenesis in cancer, vascular, rheumatoid and other disease. Nat Med 1:27-31.

Fox JC and Shanley JR (1996). Antisense inhibition of basic fibroblast growth factor induces apoptosis in vascular smooth muscle cells. J Biol Chem 271:12578-12584.

Franklin KBJ and Paxinos G (1997). The mouse brain in stereotaxic coordinates. San Diego: Academic Press.

Frisch SM and Francis H (1994). Disruption of epithelial cell-matrix interactions induces apoptosis. J Cell Biol 124: 619-626.

Frisch SM and Ruoslahti E (1997). Integrins and anoikis. Curr Opin Cell Biol 9:701-706.

Frisch SM, Vouri K, Ruoslahti E, and Chan-Hui PY (1996). Control of adhesion dependent cell survival by focal adhesion kinase. J Cell Biol 134:793-799. 
Gavrieli Y, Sherman Y, and Ben-Sasson SA (1992). Identification of programmed cell death in situ via specific labeling of nuclear DNA fragmentation. J Cell Bio 119:493-501.

Geng YJ, Wu Q, Muszynski M, Hansson GK, and Libby P (1996). Apoptosis of vascular smooth muscle cells induced by in vitro stimulation with interferon- $\gamma$, tumor necrosis factor- $\alpha$, and interleukin- $1 \beta$. Arterioscler Thromb Vasc Biol 16:19-27.

Gimbrone MA Jr, Cotran RS, Leapman SB, and Folkman J (1974). Tumor growth and neovascularization: An experimental model using the rabbit cornea. J Natl Cancer Inst 52:413427.

Goede V, Schmidt T, Kimmina S, Kozian D, and Augustin HG (1998). Analysis of blood vessel maturation processes during cyclic ovarian angiogenesis. Lab Invest 78:1385-1394.

Granville DJ, Shaw JR, Leong S, Carthy CM, Margaron P, Hunt DW, and McManus BM (1999). Release of cytochrome $c$, Bax migration, Bid cleavage, and activation of caspases 2 , $3,6,7,8$, and 9 during endothelial cell apoptosis. Am J Pathol 155:1021-1025.

Grasl-Kraupp B, Ruttkay-Nedecky B, Koudelka H, Bukowska K, Bursch W, and Schulte-Herman R (1995). In situ detection of fragmented DNA (TUNEL assay) fails to discriminate among apoptosis, necrosis, and autolytic cell death: A cautionary note. Hepatology 21:1465-1468.

Gubin A, Reddy B, Njoroge J, and Miller JL (1997). Long-term stable expression of green fluorescent protein in mammalian cells. Biochem Biophys Res Commun 236:347-350.

Holash J, Maisonpierre PC, Compton D, Boland P, Alexander CR, Zagzag D, Yancopoulos GD, and Wiegand SJ (1999). Vessel cooption, regression, and growth in tumors mediated by angiopoietins and VEGF. Science 284:1994-1998.

Honma T and Hamasaki T (1998). Ultrastructure of blood vessel regression in involution of foreign-body granuloma. $J$ Submicrosc Cytol Pathol 30:31-44.

Hungerford JE, Compton MT, Matter ML, Hoffstrom BG, and Otey CA (1996). Inhibition of pp125FAK in cultured fibroblasts results in apoptosis. J Cell Biol 135:1383-1390.

Hynes RO (1992). Integrins: Versatility, modulation, and signaling in cell adhesion. Cell 69:11-25.

Jones PL, Crack J, and Rabinovitch M (1997). Regulation of tenascin- $C$, a vascular smooth muscle cell survival factor that interacts with the alpha $v$ beta 3 integrin to promote epidermal growth factor receptor phosphorylation and growth. J Cell Biol 139:279-293.

Kagi D, Vignaux F, Ledermann B, Burki K, Depraetere V, Nagata S, Hengartner H, and Goldstein P (1994). Fas and perforin pathways as major mechanisms of T-cell-mediated cytotoxicity. Science 265:528-530.

Kayanoki Y, Fujii J, Islam K, Suzuki K, Kawata S, Matsuzawa $Y$, and Taniguchi N (1996). The protective role of glutathione peroxidase in apoptosis induced by reactive oxygen species. J Biochem 119:817-822.

Kebers F, Lewalle JM, Desreux J, Munaut C, Devy L, Foidart JM, and Noel A (1998). Induction of endothelial cell apoptosis by solid tumor cells. Exp Cell Res 240:197-205.

Kelly PJ, Suddith RL, Hutchison HT, Werrbach K, Haber B (1976). Endothelial growth factor present in tissue culture of CNS tumors. J Neurosurg 44:342-346.
Koblizek TI, Weiss C, Yancopoulos GD, Deutsch U, and Risau W (1998). Angiopoietin-1 induces sprouting angiogenesis in vitro. Curr Biol 8:529-532.

Kwak HJ, So JN, Lee SJ, Kim I, and Koh GY (1999). Angiopoietin-1 is an apoptosis survival factor for endothelial cells. FEBS Lett 448:249-253.

Leedy DA, Trune DR, Kronzo JD, Weidner N, and Cohen JI (1994). Tumor angiogenesis, the p53 antigen, and cervical metastasis in squamous carcinoma of the tongue. Otolaryngol Head Neck Surg 111:417-422.

Leithauser F, Dhein J, Mechtersheimer G, Koretz K, Burderlein S, Henne C, Schmidt A, Debatin KM, Kramer PH, and Moller P (1993). Constitutive and induced expression of APO-1, a new member of the nerve growth factor/tumor necrosis factor receptor superfamily, in normal and neoplastic cells. Lab Invest 69:415-429.

Li PF, Dietz R, and von Harsdorf R (1997). Reactive oxygen species induce apoptosis of vascular smooth muscle cell. FEBS Letters 404:249-252.

Maisonpierre PC, Suri C, Jones PF, Bartunkova S, Wiegand SJ, Radziejewski C, Compton D, McClain J, Aldrich TH, Papadopoulos N, Daly TJ, Davis S, Sato TN, and Yancopoulos GD (1997). Angiopoietin-2, a natural antagonist for Tie2 that disrupts in vivo angiogenesis. Science 277:55-60.

Majno $G$ and Joris I (1995). Apoptosis, oncosis, and necrosis: An overview of cell death. Am J Pathol 146:3-15.

Meeson A, Plamer M, Calfon M, and Lang R (1996). A relationship between apoptosis and flow during programmed capillary regression is revealed by vital analysis. Development 122:3929-3938.

Mitchell CA, Risau W, and Drexler HC (1998). Regression of vessels in the tunica vasculosa lentis is initiated by coordinated endothelial apoptosis: Role for vascular endothelial growth factor as a survival factor for endothelium. Dev Dyn 213:322-333.

Modlich U, Kaup FJ, and Augustin HG (1996). Cyclic angiogenesis and blood vessel regression in the ovary: Blood vessel regression during luteolysis involves endothelial cell detachment and vessel occlusion. Lab Invest 74:771-780.

Molnar PP, O'Neil BP, Scheitauer BW, and Grothuis DR (1999). The blood brain barrier in primary CNS lymphomas: Ultrastrucutral evidence of endothelial cell death. NeuroOncol 1:89-100.

Nagano N, Sasaki H, Aoyagi M, and Hirakawa K (1993). Invasion of experimental rat brain tumor: Early morphological changes following microinjection of C6 glioma cells. Acta Neuropathol 86:117-125.

Nagata S (1997). Apoptosis by death factor. Cell 88:355-365.

Nicosia RF and Madri J (1987). The microvascular extracellular matrix: Developmental changes during angiogenesis in the aortic ring-plasma clot model. Am J Pathol 128:78-90.

Nicosia RF, Tchao R, and Leighton J (1983). Angiogenesisdependent tumor spread in reinforced fibrin clot culture. Cancer Res 43:2159-2166.

Nicosia RF, Tchao R, and Leighton J (1986). Interactions between newly formed endothelial channels and carcinoma cells in plasma clot culture. Clin Expl Metastasis 4:91-104. 
Nor JE, Christensen J, Mooney DJ, and Polverini PJ (1999). Vascular endothelial growth factor (VEGF)-mediated angiogenesis is associated with enhanced endothelial cell survival and induction Bcl-2 expression. Am J Pathol 154:375-384.

Papapetropoulos A, Garcia-Cardena G, Dengler TJ, Maisonpierre PC, Yancopoulos GD, and Sessa WC (1999). Direct actions of angiopoietin-1 on human endothelium: Evidence for network stabilization, cell survival, and interaction with other angiogenic growth factors. Lab Invest 79:213-223.

Payne CM, Bernstein H, Bernstein C, and Garewal H (1995). Role of apoptosis in biology and pathology: Resistance to apoptosis in colon carcinogenesis. Ultrastruct Pathol 19: 221-248.

Pezzella F, Pastorino U, Tagliabue E, Andreola S, Sozzi G, Gasparini G, Menard S, Gatter K, Harris A, Fox S, Buyse M, Pilotti S, Pierotti M, and Rilke F (1997). Non-small-cell lung carcinoma tumor growth without morphological evidence of neo-angiogenesis. Am J Pathol 151:1417-1423.

Plate KH, Breier G, Weich HA, and Risau W (1992). Vascular endothelial growth factor is a potential tumour angiogenesis factor in human gliomas in vivo. Nature 359:845-848.

Pollman MJ, Naumovski L, and Gibbons GH (1999). Vascular cell apoptosis: Cell type-specific modulation by transforming growth factor- $\beta_{1}$ in endothelial cells versus smooth muscle cells. Circulation 99:2019-2026.

Re F, Zanetti A, Sironi M, Polentarutti N, Lanfrancone L, Dejana E, and Colotta F (1994). Inhibition of anchoragedependant cell spreading triggers apoptosis in cultured human endothelial cells. J Cell Biol 127:537-546.

Richardson BC, Lalwani ND, Johnson KJ, and Marks RM (1994). Fas ligation triggers apoptosis in macrophages but not endothelial cells. Eur J Immunol 24:2640-2645.

Robaye B, Mosselmans R, Fiers W, Dumond JE, and Galand P (1991). Tumor necrosis factor induces apoptosis (programmed cell death) in normal endothelial cells in vitro. Am J Pathol 138:447-453.

Ruoslahti E and Reed JC (1994). Anchorage dependance, integrins, and apoptosis. Cell 77:477-478.

Ruoslahti E (1996). Integrin signaling and matrix assembly. Tumour Biol 17:117-124.

Sato TN, Tozawa Y, Deutsch U, Wolburg-Buchholz K, Fijiwara $Y$, Gendron-Maguire M, Gridley T, Wolburg H, Risau W, and Qin Y (1995). Distinct roles of the receptor tyrosine kinases Tie-1 and Tie-2 in blood vessel formation. Nature 376:70-74.

Schaller MD, Borgman CA, Cobb BS, Vines RR, Reynolds AB, and Parsons JT (1992). pp125FAK: A structurally distinctive protein-tyrosine kinase associated with focal adhesions. Proc Natl Acad Sci USA 89:51192-51196.

Shabisgh A, Tanji N, D'Agati V, Burchardt M, Rubin M, Goluboff E, Heitjan D, Kriss A, and Buttyan R (1999). Early effects of castration on the vascular system of the rat ventral prostate gland. Endocrinology 140:1920-1926.

Shweiki D, Itin A, Soffer D, and Keshet E (1992). Vascular endothelial growth factor induced by hypoxia may mediate hypoxia-initiated angiogenesis. Nature 359:843-845.
Smith-McCune KK and Weidner N (1994). Demonstration and characterization of the angiogenic properties of cervical dysplasia. Cancer Res 54:800-804.

Stempien-Otero A, Karsan A, Cornejo CJ, Xiang H, Eunson T, Morrison RS, Kay M, Winn R, and Harlan J (1999). Mechanisms of hypoxia-induced endothelial cell death. J Biol Chem 274:8039-8045.

Suri C, McClain J, Thurston G, McDonald DM, Zhou H, Oldmixon EH, Sato TN, and Yancopoulos GD (1998). Angiopoietin-1 promotes increased vascularization in vivo. Science 282:468-471.

Tohma Y, Gratas C, Van Meir EG, Desbailets I, Tenan M, Tachibana O, Kleihues P, and Ohgaki H (1998). Necrogenesis and Fas/APO-1 (CD95) expression in primary (de novo) and secondary glioblastomas. J Neuropathol Exp Neuro 57:239245.

Valenzuela DM, Maisonpierre PC, Glass DJ, Rojas E, Nunez L, Kong Y, Gies DR, Stitt TN, Ip NY, and Yancopoulos GD (1993). Alternative forms of rat TrkC with different functional capabilities. Neuron 10:963-974.

Walker NI and Gobe GC (1987). Cell death and cell proliferation during atrophy of the rat parotid gland induced by duct obstruction. J Pathol 153:333-344.

Walker NI, Bennett RE, and Kerr JFR (1989). Cell death by apoptosis during involution of the lactating breast in mice and rats. Am J Anat 185:19-32.

Wyllie AH, Kerr JFR, and Currie AR (1980). Cell death: The significance of apoptosis. Int Rev Cytol 68:251-306.

Xu LH, Owens LV, Sturge GC, Yang X, Liu ET, Craven RJ, and Cance WG (1996). Attenuation of the expression of the focal adhesion kinase induces apoptosis in tumor cells. Cell Growth Differ 7:413-418.

Yamada KM and Miyamoto S (1995). Integrin transmembrane signaling and cytoskeletal control. Curr Opin Cell Biol 7:681689.

Yancopoulos GD, Klagsbrun M, and Folkman J (1998). Vasculogenesis, angiogenesis, and growth factors: Ephrins enter the fray at the border. Cell 93:661-664.

Zagzag D (1995). Angiogenic factors in neural embryogenesis and neoplasia. Am J Pathol 146:293-309.

Zagzag D, Friedlander DR, Dosik J, Chikramane S, Chan W, Greco MA, Allen JC, Dorovini-Zis K, and Grumet M (1996). Tenascin- $C$ expression in angiogenic vessels in human astrocytomas and by human brain endothelial cells in vitro. Cancer Res 56:182-189.

Zagzag D, Hooper A, Friedlander DR, Chan W, Holash J, Wiegand SJ, Yancopoulos GD, and Grumet M (1999). In situ expression of angiopoietins in astrocytomas identifies angiopoietin-2 as an early marker of tumor angiogenesis. Exp Neurol 159:391-400. 